EVS28

KINTEX, Korea, May 3-6, 2015

\title{
Chevrolet Volt On-Road Test Programs in Canada. Part 2: Evaluation of Gasoline Displacement and Extreme Weather Performance in Comparison with Other Vehicles Types
}

\author{
Hajo Ribberink ${ }^{1}$, Aaron Loiselle-Lapointe ${ }^{2}$ and Aaron Conde ${ }^{2}$ \\ ${ }^{1}$ Natural Resources Canada, 1 Haanel Drive, Ottawa, Canada K1A 1 M1 (Hajo.Ribberink@nrcan.gc.ca) \\ ${ }^{2}$ Environment Canada, 335 River Road, Ottawa, Canada K1A OH3 (Aaron.Conde@ec.gc.ca; Aaron.Loiselle- \\ Lapointe@ec.gc.ca)
}

\begin{abstract}
Two test programs were conducted to investigate the on-road performance of model year 2012 Chevrolet Volts in Ottawa, Ontario, Canada. Specific testing routes were defined for various types of city and highway driving. Data loggers and additional instrumentation were installed in the vehicles to accurately monitor variables indicating the use of electricity for driving, as well as the use of fuel by the gasoline engine. The vehicles were tested during various seasons of the year to record their performance over the full range of climate conditions representative for a large part of Canada (from $-27^{\circ} \mathrm{C}$ to $+37^{\circ} \mathrm{C}$ ).

The test results were subsequently processed and analysed to compare the Volt's performance in charge depletion mode (electric drive) to its operation in charge sustaining mode (hybrid drive). A 'Gasoline Displacement Factor' was introduced, which reflects the amount of grid electricity needed to replace one litre of gasoline used for driving the Volt. Test results show very low Gasoline Displacement Factors of 2 $3.5 \mathrm{kWh} / \mathrm{L}$ for summer driving, while values of $3-9 \mathrm{kWh} / \mathrm{L}$ were observed for winter driving.

The test results were also used to evaluate the additional amount of energy that the vehicles would need for driving, and cabin conditioning (heating in winter, air conditioning in summer) under conditions different from the more optimal $20-25{ }^{\circ} \mathrm{C}$ temperature range used for most standard performance tests. The Volt's relative performance under extreme temperature conditions was compared to those of conventional gasoline vehicles, hybrid electric vehicles and battery electric vehicles. Additionally, recommendations for a more optimal use of the Volt under extreme temperature conditions are provided.
\end{abstract}

Keywords: Electric vehicle, On-road testing, Extreme temperatures, Performance, Gasoline displacement

\section{Introduction}

National emission and fuel consumption standards are becoming ever more stringent worldwide.
Plug-in hybrid electric vehicle (PHEV) sales are one of several critical methods for original equipment manufacturers (OEMs) to meet the next round of emissions and fuel consumption 
regulations in North America [1]. PHEVs are capable of emitting no in-use exhaust pollutants and consuming no petrol, but have an internal combustion engine (ICE) to propel the vehicle when the battery is depleted, mitigating range anxiety and increasing the likelihood of consumer acceptance.

But like all vehicles, the performance of a PHEV is not fully captured in compliance tests, which are conducted in an environmentally controlled chamber. As such, PHEV owners may not realize the best performance of their vehicle, depends on their driving habits and environmental conditions. Massive studies have been undertaken to fill in this performance matrix for PHEVs, most by utilizing on-board CANbus dataloggers [2, 3]. These studies serve to shed light on the performance a consumer can expect from their PHEV during different scenarios, but as yet, there are few published studies $[3,4]$ that explore realworld performance of a PHEV in Canadian driving conditions.

In 2013, Natural Resources Canada (NRCan) and Environment Canada (EC) concurrently and independently started testing two 2012 Chevrolet Volt PHEVs in Canadian climate encountered throughout the year. Testing for both studies lasted more than one year each to capture a representative subset of temperatures and weather conditions one could expect in Eastern Ontario throughout the year; in this case, $-27{ }^{\circ} \mathrm{C}$ to $+37^{\circ} \mathrm{C}$. Jointly, more than 1300 trips were run between 2013 and 2014.

Due to the volume and breadth of data accumulated from the NRCan and EC studies, two papers have been written. The first paper [5] provides a detailed account of the experimental method and an overall summary of the electric range and energy consumption results in relation to driving pattern, ambient temperature and accessory usage. This paper describes a novel approach to quantifying a gasoline displacement factor based on electricity use, as well as a detailed analysis of the vehicle performance of the Volt as a function of ambient temperature and a comparison of the temperature dependent performance to that of other vehicle technologies. The results from these studies have already been provided to several entities conducting grid impact modelling and may be available for further distribution upon request.

\section{Experimental Method}

In 2013, EC and NRCan independently undertook concurrent projects to test identical model
Chevrolet Volts under Canadian conditions on roads in Ottawa, Ontario. Testing of both vehicles was completed by 2014 . While the test methods for both projects were not aligned, many similarities existed, such that analysis of the combined results was both suitable and advantageous, due to the increased sample size and test conditions.

A detailed description of the experimental method used in the EC and NRCan projects may be found in the first paper [5]. A summary of this description is provided here to facilitate the independent reading of this paper.

\subsection{Vehicle Specifications}

NRCan and EC tested two identical models of the 2012 Chevrolet Volt under different conditions and driving routes. The specifications of the two Volts are provided in Table 1. In the remainder of the paper, the Volt tested by EC will be referred to as 'Volt 1', while 'Volt 2' will be used for the Volt tested by NRCan.

Table 1: Specifications of the EC and NRCan Chevrolet Volts

\begin{tabular}{|c|c|c|}
\hline Parameter & EC Volt & NRCan Volt \\
\hline Vehicle Name & Volt 1 & Volt 2 \\
\hline Model Year & 2012 & $\leftarrow$ Same \\
Modal and Trim & Volt & $\leftarrow$ Same \\
\hline Make & Chevrolet & $\leftarrow$ Same \\
VIN & 1G1RA6E45CU103150 & 1G1RA6E41CU100911 \\
\hline Engine & ECOTEC DOHC I-4 & $\leftarrow$ Same \\
\hline Power Train & FWD & $\leftarrow$ Same \\
Engine Size [cm $\left.{ }^{3}\right]$ & 1398 & $\leftarrow$ Same \\
Power [kW @ rpm] & 63 @ 4800 & $\leftarrow$ Same \\
\hline Speed [rpm] & 4800 (est.) & $\leftarrow$ Same \\
$\begin{array}{c}\text { Fuel Tank Volume [L] } \\
\text { All Electric Range [km] }\end{array}$ & 35 & $\leftarrow$ Same \\
\hline GVWR [kg] & 2053 & $\leftarrow$ Same \\
\hline $\begin{array}{c}\text { Curb Weight [kg] } \\
\text { Est. Test Weight [kg] }\end{array}$ & 1721 & $\leftarrow$ Same \\
\hline $\begin{array}{c}\text { Battery Energy [kWh] } \\
\text { Available Modes }\end{array}$ & 2035 & $\leftarrow$ Same \\
\hline $\begin{array}{c}\text { Drive Motor Power } \\
\text { [kW] }\end{array}$ & 16 & 1806 (est.) \\
\hline $\begin{array}{c}\text { Generator Motor } \\
\text { Power [kW] }\end{array}$ & 111 & $\leftarrow$ Same \\
\hline $\begin{array}{c}\text { Odometer at Start of } \\
\text { Program [km] }\end{array}$ & 55 SREV, Hybrid & $\leftarrow$ Same \\
\hline $\begin{array}{c}\text { Odometer at End of } \\
\text { Program [km] }\end{array}$ & 10200 & $\leftarrow$ Same \\
\hline
\end{tabular}

\subsection{Drive Schedules}

Volt 1 was tested over 7 different routes, each representing a different driving style and all within close proximity to the EC laboratory.

These 7 drive routes include two city routes (City 1 and 2), two primary arterial routes (Arterial 1 
Table 2: Volt 1 and Volt 2 drive cycle characteristics for summer/winter tests

\begin{tabular}{|c|c|c|c|c|c|c|c|c|c|c|}
\hline Drive Cycle & $\begin{array}{c}\text { Average } \\
\text { Speed } \\
\text { (kph) }\end{array}$ & $\begin{array}{c}\text { St. Dev. } \\
\text { Speed }\end{array}$ & $\begin{array}{c}\text { Max } \\
\text { Speed } \\
\text { (kph) }\end{array}$ & $\begin{array}{c}\text { Max } \\
\text { Accel } \\
\text { (kph/s) }\end{array}$ & $\begin{array}{c}\text { Max } \\
\text { Decel } \\
\text { (kph/s) }\end{array}$ & $\begin{array}{c}\text { Idle } \\
\text { Time (s) }\end{array}$ & \% Idling & $\begin{array}{c}\text { No. of } \\
\text { Idle } \\
\text { Periods }\end{array}$ & $\begin{array}{c}\text { Distance } \\
\text { (km) }\end{array}$ & $\begin{array}{c}\text { Time } \\
\text { (min) }\end{array}$ \\
\hline City 1 & $37 / 37$ & $24 / 23$ & $77 / 77$ & $9 / 9$ & $-11 /-12$ & $204 / 142$ & $13 \% / 10 \%$ & $7 / 7$ & $16 / 15$ & $26 / 25$ \\
\hline City 3 & $/$ & $/$ & $/$ & $/$ & $/$ & $/$ & $/$ & $/$ & $7 / 7$ & $14 / 15$ \\
\hline Highway & $57 / 49$ & $28 / 29$ & $83 / 84$ & $6 / 6$ & $-9 /-7$ & $9 / 78$ & $1 \% / 10 \%$ & $2 / 4$ & $10 / 10$ & $11 / 13$ \\
\hline 416Express & $/$ & $/$ & $/$ & $/$ & $/$ & $/$ & $/$ & $/$ & $19 / 19$ & $15 / 14$ \\
\hline
\end{tabular}

and 2), one Congested route, one Highway route, and one Expressway route (417Express). In this paper, the results of the City 1 and Highway routes for Volt 1 are used to contrast the results of Volt 2 on the City 3 and 416Express test routes. Using GPS measurements, the average drive cycle characteristics for winter and summer tests for these 4 cycles are presented in Table 2. Due to limited GPS data from Volt 2 some information is not available for the 416Express and City 3 routes.

\subsection{Test Setup}

Because the Volt 1 and 2 projects were conducted independently and without initial collaboration there exist inherent differences in the test setup and procedure; these are listed in Table 3.

Table 3: Differences between Volt 1 and Volt 2 Test Conditions

\begin{tabular}{|c|c|c|}
\hline Test Condition & Volt 1 & Volt 2 \\
\hline Cold-Start in CD mode & Yes & No \\
\hline $\begin{array}{l}\text { Single-Cycle Full } \\
\text { Depletion Tests }\end{array}$ & City 1 and Highway Only & No \\
\hline $\begin{array}{l}\text { Preconditioned with } \\
\text { test cycle }\end{array}$ & Yes & Mostly No \\
\hline $\begin{array}{c}\text { Tests run in all weather } \\
\text { conditions }\end{array}$ & $\begin{array}{c}\text { No (avoided adverse } \\
\text { weather) }\end{array}$ & $\begin{array}{l}\text { No (avoided high winds } \\
\text { and precipitation) }\end{array}$ \\
\hline $\begin{array}{c}\text { Accessory } \\
\text { Temperature Settings }\end{array}$ & $\begin{array}{c}\text { Winter: Auto defrost } \\
\text { Medium Fan @ } 22^{\circ} \mathrm{C} \\
\text { Summer: Medium Fan @ } \\
22^{\circ} \mathrm{C}\end{array}$ & $\begin{array}{l}\text { Winter: Auto defrost Auto } \\
\text { Fan @ } 22^{\circ} \mathrm{C} \\
\text { Summer: Auto Fan @ } \\
23^{\circ} \mathrm{C}\end{array}$ \\
\hline $\begin{array}{c}\text { Drive to Route Start } \\
\text { Point }\end{array}$ & No (start at facility) & $\begin{array}{c}\text { Yes (4km and } 12 \mathrm{~km} \\
\text { distances) }\end{array}$ \\
\hline $\begin{array}{l}\text { Section-to-Section } \\
\text { Soak Duration }\end{array}$ & 2-3 minutes & 2-3 minutes \\
\hline $\begin{array}{l}\text { Repeat-to-Repeat } \\
\text { Soak Duration }\end{array}$ & 12 minutes & 2-3 minutes \\
\hline Vehicle Test Weight & $2035 \mathrm{~kg}$ & $1806 \mathrm{~kg}$ est. \\
\hline $\begin{array}{c}\text { Number of Passengers } \\
\text { (Including Driver) }\end{array}$ & 2 & 1 or 2 \\
\hline
\end{tabular}

Volt 1 was preconditioned 12-36 hours before each test by driving it over the intended test route in either CS or CD mode. Afterwards, and after all tests, Volt 1 was charged outside without any external pre-warming equipment (except for the protection of on-board instrumentation). Each test began immediately upon starting the vehicle and each repeat of all cycles were separated from the next with a 12 minute soak period. In between the two sections of the Highway cycle, the Volt 1 was soaked for approximately two minutes, while technicians made notes and reset instrumentation. Testing was aborted in adverse weather conditions (i.e. snow, icy roads and rain). Test routes were conducted first in CD mode for as many times as required to deplete the battery, and then in $\mathrm{CS}$ mode for one full test repeat.

Volt 2 was not preconditioned before a test and was driven $4 \mathrm{~km}$ and $12 \mathrm{~km}$ away from the NRCan facility before the City 3 and 416Express tests were started, respectively. As such, Volt 2 was (partly) warmed up by the time the City 3 or 416Express test was initiated. Tests were conducted by cold-starting in CD mode. Once the battery charge was fully depleted multiple repeats of CS tests were conducted if time permitted. For longer duration tests, the CS mode was tested on a separate day with ambient temperatures matching those of the test day with comparable CD mode testing. The Volt 2 was soaked for two to three minutes in between each repeat test and in between each section of a cycle.

\subsection{Instrumentation and Data Acquisition}

Volt 1 was outfitted with a large number of instruments to record many details of the vehicle's performance: a portable emission measurement system (PEMS), high-speed exhaust flow tube, GPS unit and relative humidity (RH) sensor, a HIOKI Power Analyser and amp probes, a CANbus OBD datalogger, a digital datalogger and a gasoline generator to supply the electricity demand of the instrumentation.

While the EC project (Volt 1) relied heavily on external sensors and instrumentation, the NRCan project (Volt 2) took advantage of the available information from the vehicle dash, a ChargePoint web application, and from a FleetCarma C5 Datalogger, programmed to record summary information from each trip (a trip is defined as the duration between the initiation and shutdown of vehicle CANbus systems).

Further details on the instruments and measured parameters for both Volts can be found in [5]. 


\subsection{Test Matrix}

Table 4 presents the test matrix for Volt 1 and Volt 2 all-electric tests conducted on their specific city and highway test routes. Testing at EC was focussed on capturing specific vehicle performance under summer and winter conditions, while the objective of the Volt 2 tests was to cover the full range of temperatures over all seasons. Summer test temperatures varied between $17{ }^{\circ} \mathrm{C}$ and $37{ }^{\circ} \mathrm{C}$, and winter test temperatures ranged from $-27^{\circ} \mathrm{C}$ to $12{ }^{\circ} \mathrm{C}$.

Table 4: Test Matrix for the EC and NRCan city and highway On-Road Volt testing

\begin{tabular}{|c|c|c|c|}
\hline \multirow{2}{*}{ Activity } & \multirow{2}{*}{ Season } & \multicolumn{2}{|c|}{ Repeats } \\
\cline { 3 - 4 } & & Volt 1 & Volt 2 \\
\hline City 1 & Winter & 6 & - \\
& Summer & 5 & - \\
City 3 & Winter & - & 5 \\
& Summer & - & 3 \\
Highway & Winter & 5 & - \\
& Summer & 4 & - \\
416Express & Winter & - & 5 \\
& Summer & - & 5 \\
\hline
\end{tabular}

\section{Results and Discussion}

\subsection{Temperature dependent vehicle performance}

Volt 2 was extensively tested over the City 3 and 416Express test routes over the full range of temperatures experienced in large parts of Canada over a year. First, the results for all repeats of a test cycle driven in Charge Depleting (CD) mode on a test day were aggregated into the overall specific electricity consumption rate per cycle for the specific testing temperature on that day.

Equation 1 describes the calculation method used for calculating the specific DC electricity consumption from the battery $\left(E C d c_{c y c l e}\right)$,

$E C d c_{\text {cycle }}=\frac{\sum_{i=1}^{n} E d c_{\text {cycle } i}}{\sum_{i=1}^{n} D_{\text {tot } i}}$

where $E d c_{\text {cycle } i}$ is the total DC battery energy (Wh) discharged during repeat $i$ (of the $n$ cycle repeats driven during the test), and $D_{\text {tot } i}$ is the total distance $(\mathrm{km})$ travelled for repeat $\mathrm{i}$ of a specific cycle.
After the testing, Volt 2 was always parked outside and on most days recharged using a Level $2(3.3 \mathrm{~kW})$ charger. On some days, the Level 2 charger was not available and a Level $1(1.3 \mathrm{~kW})$ charger was used. The efficiency of the charging process $\left(C h_{e f f}\right)$ is defined as the ratio between the AC grid energy supplied (Eac grid, in Wh) to fully replenish the battery charge and the total DC electricity supplied by the battery during previous driving $\left(E d c_{\text {battery }}\right.$, in Wh).

$$
\begin{aligned}
& C h_{\text {eff }}=\frac{E d c_{\text {battery }}}{E a c_{\text {grid }}} \times 100 \% \\
& E d c_{\text {battery }}=\sum_{i=0}^{n} E d c_{\text {cycle } i}
\end{aligned}
$$

In Equation 3, all additional driving before or after the testing, which would also deplete the battery, is represented by 'cycle 0 '.

The efficiency of the Level 2 charging process was recorded for Volt 2 recharge events after days with testing on the City 3 or 416Express drive cycles. The correlation between charging efficiency and the ambient temperature is displayed in Figure 1. The results show a slight decrease in efficiency for very low and very high ambient temperatures, which could be related to additional power consumption by the Volt's thermal management system to condition the battery during the recharging process. Unfortunately, not all test days provided Level 2 charging data. However, missing data points could comfortably be estimated either by interpolation between neighbouring data points or by using charging efficiency results from days with comparable driving and weather conditions.

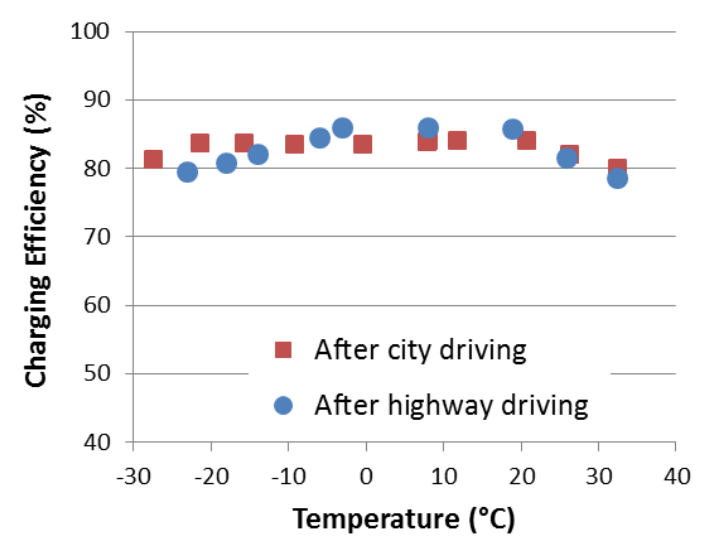

Figure 1: Charging efficiencies for Level 2 recharging $(3.3 \mathrm{~kW})$ of Volt 2 after testing on the City 3 city and 416Express highway routes. 


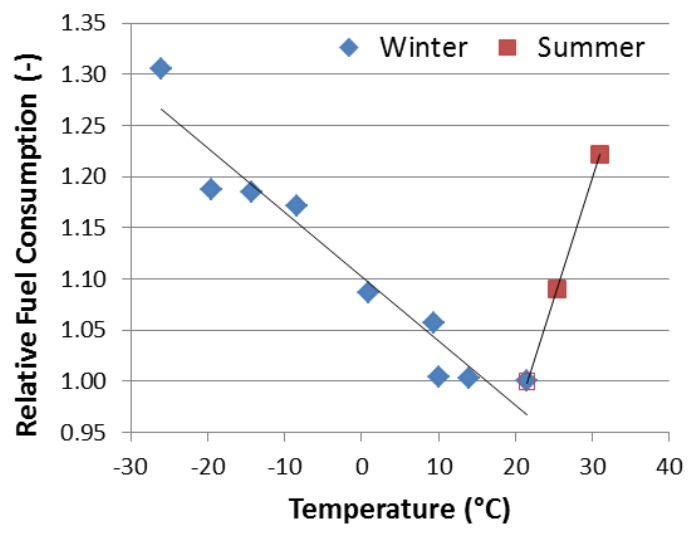

a) City driving (City 3)

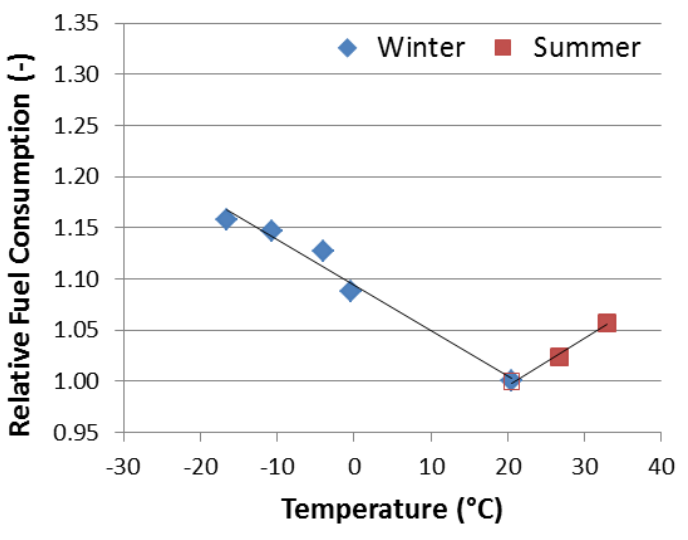

b) Highway driving (416Express)

Figure 2: Comparison of relative amounts of fuel consumption of Volt 2 in Charge Sustaining (CS) mode as a function of ambient temperature, for a) city driving and b) highway driving

Similar to Equation 1, the results for the gasoline consumption by the internal combustion engine (ICE) during Charge Sustaining (CS) mode were used to calculate the specific gasoline consumption $\left(G C_{c y c l e}\right)$ of a cycle:

$G C_{\text {cycle }}=\frac{\sum_{i=1}^{n} G_{\text {cycle } i}}{\sum_{i=1}^{n} D_{\text {tot } i}}$

In this equation, $G_{\text {cycle } i}$ is the gasoline consumption (L) of repeat $\mathrm{i}$ of a specific cycle. Equation 4 was also used to calculate the specific gasoline consumption of trips driven in $\mathrm{CD}$ mode in winter, during which the Volt would intermittently operate the ICE to assist in heating the cabin and/or the battery, as well as providing propulsion power.

Figure 2 presents the gasoline consumption results for City 3 and 416Express tests performed with Volt 2 in CS mode at various ambient temperatures. Most vehicles display optimal performance at temperatures of $20-25^{\circ} \mathrm{C}$, when the additional energy consumption for cabin conditioning is minimal. The CS mode test results were therefore normalized to 'Relative Fuel Consumption' results by dividing the specific gasoline consumption for testing at a certain temperature $\mathrm{T}$ by the specific gasoline consumption for testing at around $22{ }^{\circ} \mathrm{C}$ (Eq. 5). Using this approach, the increase in fuel consumption for operating Volt 2 at different temperatures was plotted in Figure 2.

Rel.Fuel Cons. $(T)=\frac{G C_{c y c l e}(T)}{G C_{c y c l e}\left(22^{\circ} C\right)}$
The results in Figure 2 show a linear or weak $2^{\text {nd }}$ order correlation between the Volt 2 fuel consumption in CS mode and ambient temperatures in winter. City driving displays a larger increase in relative fuel consumption than highway driving. In summer, the rise in fuel consumption related to supplying air conditioning to the cabin is lower than the increase in fuel for driving in winter, especially for the 416Express highway cycle.

The results of the Volt 2 testing in CD mode were processed in a similar way as the CS mode fuel consumption results. The DC electricity draws from the battery for testing Volt 2 in a specific drive cycle and at a certain ambient temperature, $E C d c_{\text {cycle }}(T)$, were first converted into AC loads, $\operatorname{ECac}_{\text {cycle }}(T)$, using Eq. 2 and the charging efficiency data displayed Figure 1. Then 'Relative Electricity Consumption' results were calculated using Equation 6.

Rel.Elec.Cons. $(T)=\frac{\operatorname{ECac}_{c y c l e}(T)}{\operatorname{ECac_{cycle}(22^{\circ }\mathrm {C})}}$

Figure 3 presents the Relative Electricity Consumption results for testing Volt 2 at various ambient temperatures in city (City 3) and highway (416Express) driving. As for the results in CS mode in Figure 2, the influence of cabin heating and cooling on the energy consumption of the Volt was much greater in city driving than for highway driving. This is caused by the fact that vehicles in highway driving require an average two to three times higher power output to propel the vehicle. The additional energy for cabin 
conditioning at extreme temperatures will then be a smaller fraction of the total energy requirement. The data displayed in Figure 3 can be grouped into three distinct clusters of results, corresponding to the different modes of operation for the Volt in the various seasons of the year.

1. In summer, the electricity consumption of the Volt increased with the need for air conditioning at more extreme temperatures. The relative increase in electricity consumption for operating the Volt in $\mathrm{CD}$ mode is comparable to the increase in fuel consumption in CS mode.

2. At temperatures below $20{ }^{\circ} \mathrm{C}$ (in spring or fall), the electricity consumption of the Volt significantly increased due to the additional load for cabin heating. This increase is much higher than in CS mode, when excess heat from the ICE is readily available to heat the cabin.

3. At winter temperatures below $-5{ }^{\circ} \mathrm{C}$, the Volt intermittently operated the ICE to assist in heating the cabin and its battery, and powering the vehicle. The frequency of using the ICE increased at lower temperatures. This effect was strongest in city driving, where at extremely low temperatures the gasoline consumption in CD mode approached the CS mode gasoline consumption for driving at $22{ }^{\circ} \mathrm{C}$. As a consequence of the frequent operation of the ICE, the output from the battery was clearly reduced under these conditions. During highway driving, the ICE was less frequently engaged, resulting in a more or less constant power supply from the battery at sub-zero temperatures. A comparison between the increase in electricity and fuel consumption in CD mode and the larger fuel consumption in CS mode for winter driving is not easy to make, because of the two different energy sources used while driving in $\mathrm{CD}$ mode. However, the increase in gasoline consumed by the ICE in

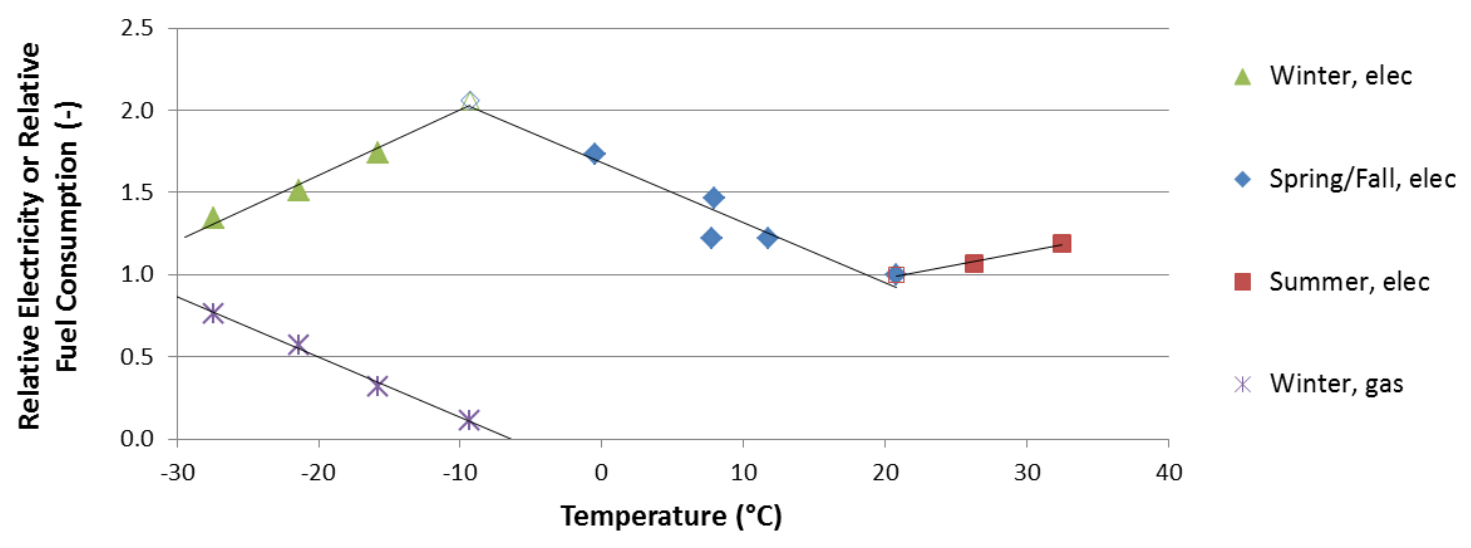

a) City driving (City 3$)$

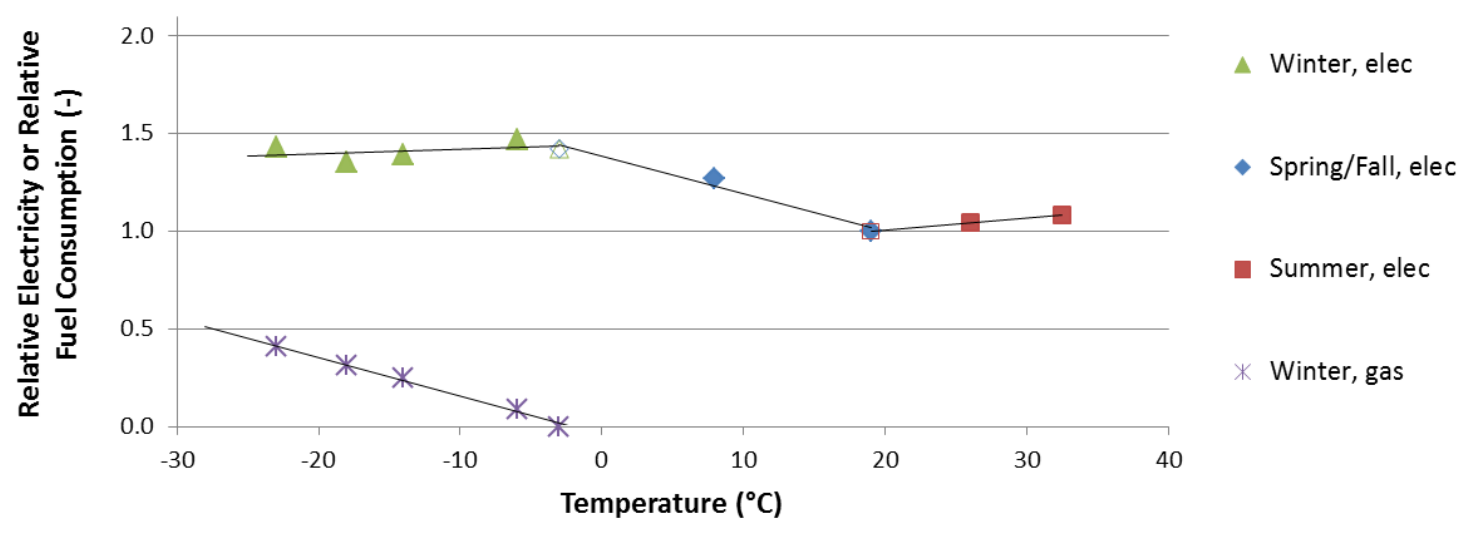

b) Highway driving (416Express)

Figure 3: Comparison of relative amount of electricity and fuel consumption of Volt 2 in Charge Depletion (CD) mode as a function of ambient temperature, for a) city driving and b) highway driving 
CD mode at very low temperatures was approximately twice the increase in fuel consumption during CS mode under these conditions. This indicates that the increase in energy consumption in $\mathrm{CD}$ mode was much higher than in CS mode.

The graph for city driving in Figure 3 shows two data points for testing at around $8{ }^{\circ} \mathrm{C}$. Although the ambient temperature was the same during testing on these days, there is a significant difference in the electricity consumption. This difference was attributed to the Volt being soaked at colder temperatures before the test and the Volt operating the auto defrost during the tests with the higher electricity consumption.

\subsection{Gasoline Displacement Factor}

While Volt 2 was tested over the City 3 and 416Express cycles, Volt 1 was tested over the City 1 and Highway routes (amongst others), in both operating modes (CS and CD) in summer and winter. Comparison of the results for driving in CD mode and in CS mode will create insight in the relative efficiency of these operating modes of the Volts over the various seasons and driving cycles. As a metric for the relative performance of the Volt, a 'Gasoline Displacement Factor' (GDF) is introduced, which indicates how many $\mathrm{kWh}$ of AC grid electricity were needed for the Volt to do the same driving in $\mathrm{CD}$ mode as one litre of gasoline would allow under identical conditions in CS mode. For summer test results, the GDF is calculated using Equation 7.

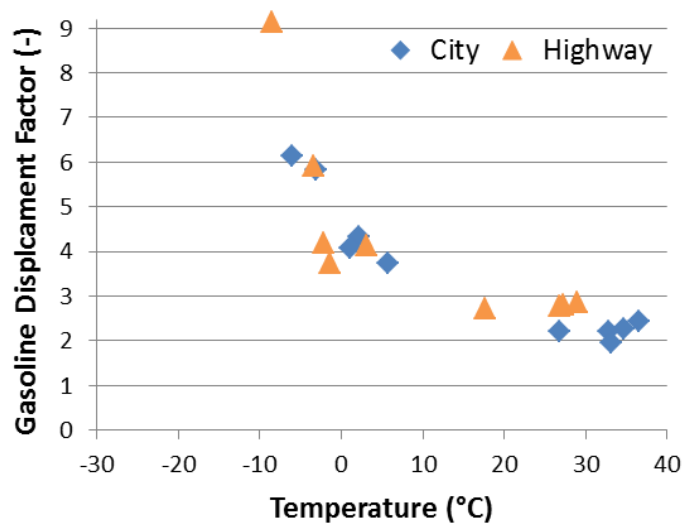

a) Volt 1

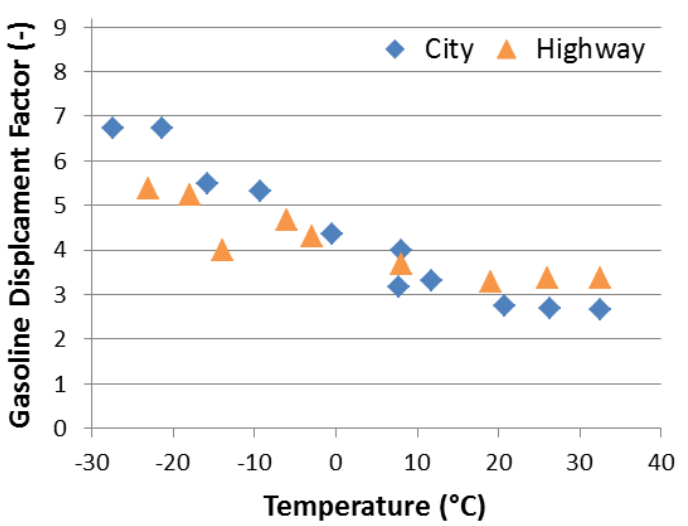

b) Volt 2

Figure 4: Gasoline Displacement Factors as a function of ambient temperature and for different driving cycles, for a) Volt 1 and b) Volt 2

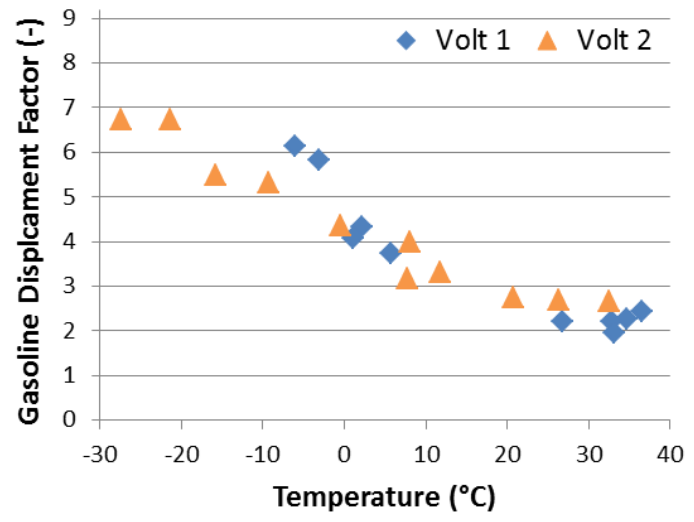

a) City driving

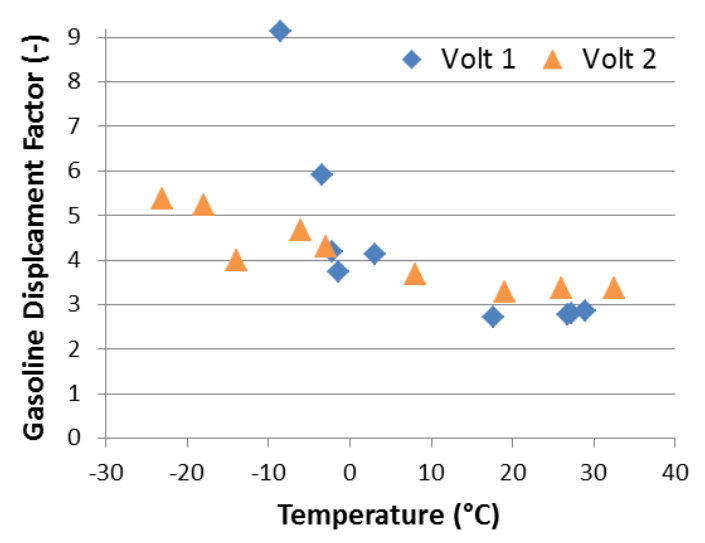

b) Highway driving

Figure 5: Gasoline Displacement Factors for Volt 1 and Volt 2 as a function of ambient temperature, for a) city driving and b) highway driving 
When the ICE would also be operated in CD mode testing in winter, the fuel consumed in $\mathrm{CD}$ mode $\left(G C_{\text {cycle-CD }}\right)$ is subtracted from the CS mode gasoline consumption $\left(G C_{c y c l e-C S}\right)$ in calculating the GDF (Equation 8).

$$
\begin{aligned}
& G D F=\frac{E \operatorname{Eac}_{\text {cycle }}(T)}{G C_{\text {cycle }}(T)} \\
& G D F=\frac{E C a c_{\text {cycle }}(T)}{G C_{\text {cycle }-C S}(T)-G C_{\text {cycle }-C D}(T)}
\end{aligned}
$$

Figure 4 presents the GDFs for Volt 1 and Volt 2 in separate graphs. In each graph the GDF is shown for various temperatures and for city and highway driving. Both Volts show strong increases in GDFs in winter, especially for city driving. The energy content of one litre of gasoline is roughly equivalent to $9 \mathrm{kWh}$ of $\mathrm{AC}$ grid electricity. Figure 4 shows GDF values of 2.0 - 3.5 for the Volts in summer, indicating the superior efficiency of the electric drive train. In winter, however, this advantage is mostly lost due to the intermittent operation of the ICE. This intermittent operation of the ICE in CD mode is relatively inefficient compared to its mostly full time operation in CS mode. Depending on the price ratio between gasoline and electricity, it may be more economical for Volt owners to drive their vehicle in CS mode at very cold temperatures and postpone electric driving until temperatures are less extreme. Similarly, Volt drivers, who know they will deplete the Volt's battery during their commute to work, may opt to drive in CS mode in the morning and preserve the electricity in the battery for more efficient $\mathrm{CD}$ mode driving at higher ambient temperatures in the afternoon.

To more easily compare the results for Volt 1 and Volt 2, the GDFs have been rearranged in separate graphs for city and highway driving in Figure 5. Despite the differences in drive cycles and test methods, the results for both Volts are much alike. Volt 1 has slightly lower GDFs in summer, but higher ones in winter. The latter is related to Volt 1 having much longer soak periods between repeats of the same test cycle than Volt 2.

\subsection{Comparison of temperature dependent vehicle performance for different vehicle types}

The results for the temperature dependency of the performance of Volt 2 were compared to similar data from standard city and highway drive cycle tests performed with representative Conventional Vehicles (CVs), Hybrid Electric Vehicles (HEVs) and Battery electric vehicles (BEVs). Data for three CVs and three HEVs were downloaded from [6], while results for BEVs came from the testing of three BEVs, owned by the ecoTECHNOLOGY for Vehicles Program of Transport Canada. These vehicles were tested by Environment Canada through funding of Transport Canada. Unfortunately, the data available for the other vehicles types did not cover as broad a temperature range as the testing of Volt 2, and sometimes data was only available from very few vehicles. However, the data available should still give a reasonable indication of the temperature dependency of the performance of these different vehicle types.

The data for CVs, HEVs, and BEVs were not gathered during actual on-road testing, but through dynamometer testing using industry standard drive cycles for city and highway driving (LA4 and HWFCT). These cycles were developed several decades ago [7] and are known to be less representative of current day aggressive driving. However, as the results are only used to compare the relative performance at various temperatures, these differences in drive cycles were expected to be of less significance.

Figure 6 presents the Relative Fuel Consumption for CVs, HEVs and Volt 2 driven in CS mode, in summer and winter driving over city and highway routes. In winter, the relative performance of all vehicles types is similar; except for HEVs in city driving. Under these conditions, all investigated HEVs show a much larger increase in relative fuel consumption than the CVs or the Volt. The relative performance of the Volt in summer is much better than that of the CVs and HEVs. The Volt shows a significantly smaller increase in relative fuel consumption when using air conditioning, especially over the 416Express cycle.

The relative performance of the Volt in CD mode is compared to the relative efficiency of a number of BEVs in Figure 7. In summer, the BEV shows a slightly higher increase in electricity consumption for driving with air conditioning at extreme temperatures in both city and highway driving. The increase in power consumption during spring and fall for the Volt matches the trend for the BEV on the highway, but is slightly higher in city driving. A direct comparison for winter driving is hard to make due to the two different energy sources used in the Volt. 


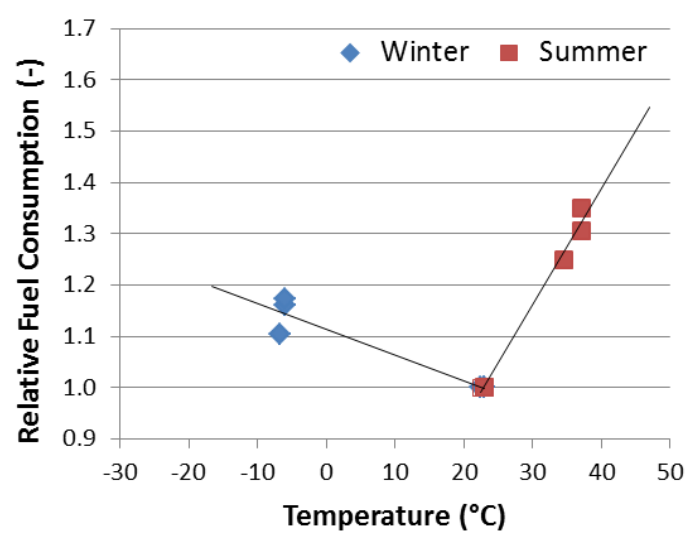

a) $\mathrm{CV}$, city driving

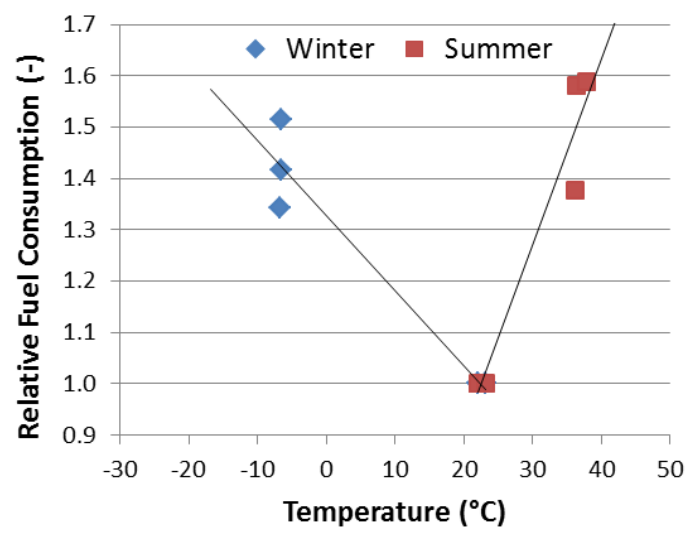

b) HEV, city driving

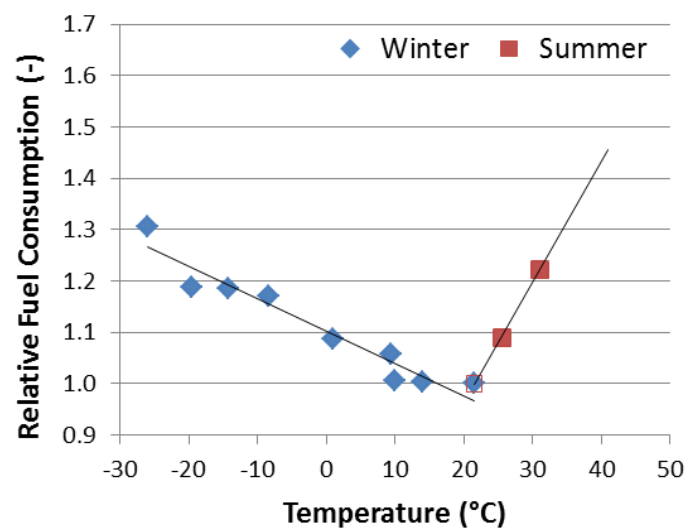

c) PHEV (Volt 2), city driving

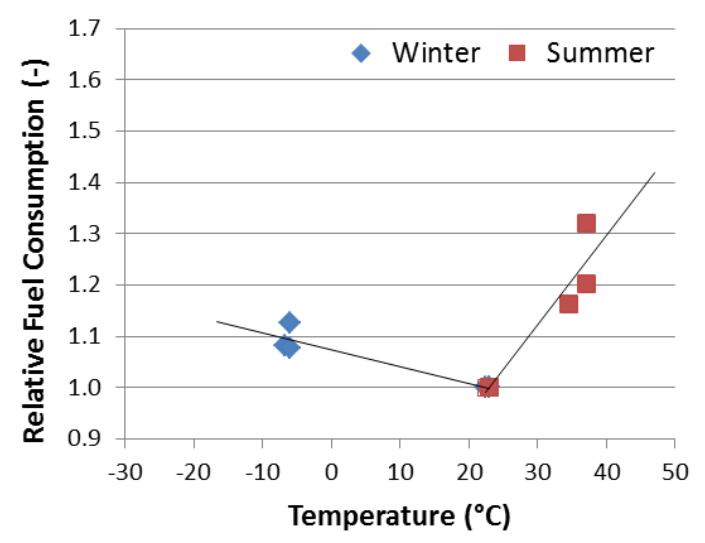

d) $\mathrm{CV}$, highway driving

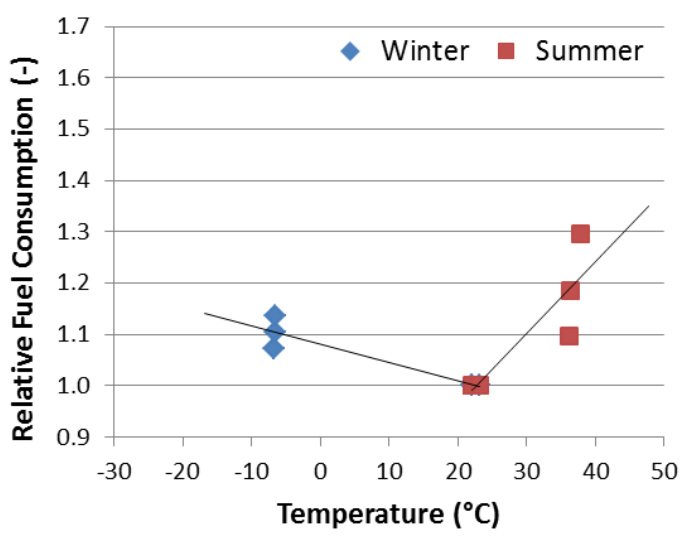

e) HEV, highway driving

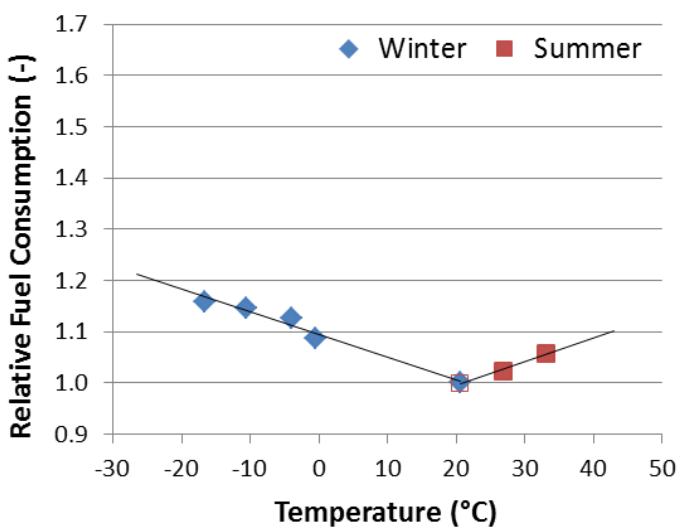

f) PHEV (Volt 2), highway driving

Figure 6: Comparison of the relative energy consumption for City and Highway driving for Conventional Vehicles (graphs a) and d)), Hybrid Electric Vehicles (graphs b) and e)), and the Volt 2 Plug-in Hybrid Electric Vehicle (graphs c) and f)) driven in Charge Sustaining mode.

However, the GDFs shown in Figure $4 b$ can be used to convert the gasoline consumption of Volt 2 in $\mathrm{CD}$ mode at cold temperatures to calculate a surrogate 'electricity only' consumption. For 416Express driving, a Relative
Electricity Consumption of 1.95 is calculated for the Volt for an ambient temperature of $-20{ }^{\circ} \mathrm{C}$. This value is not much higher than the 1.8 value for the BEV under these conditions. The Volt clearly performs worse than the BEVs in city 


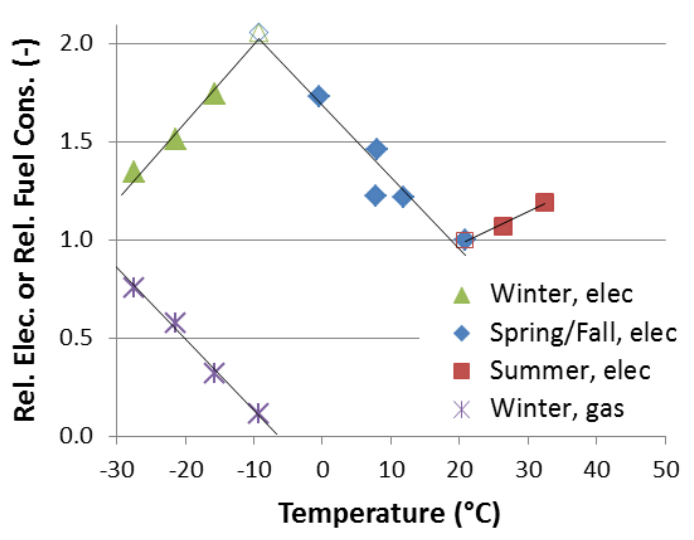

a) PHEV (Volt 2), city driving

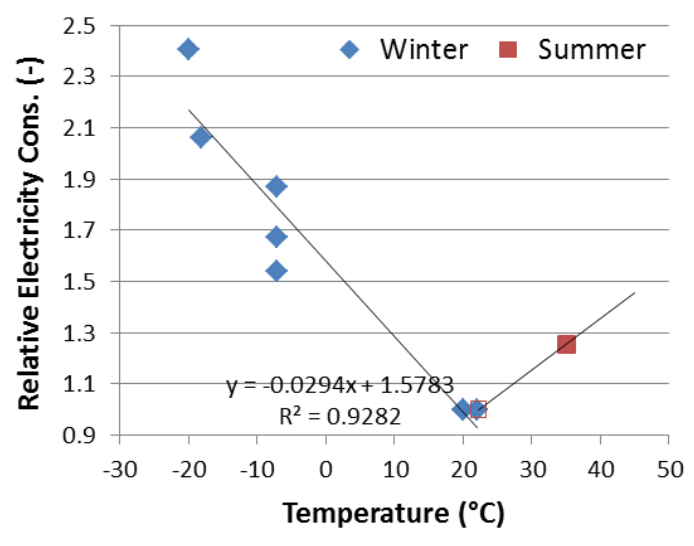

b) BEV, city driving

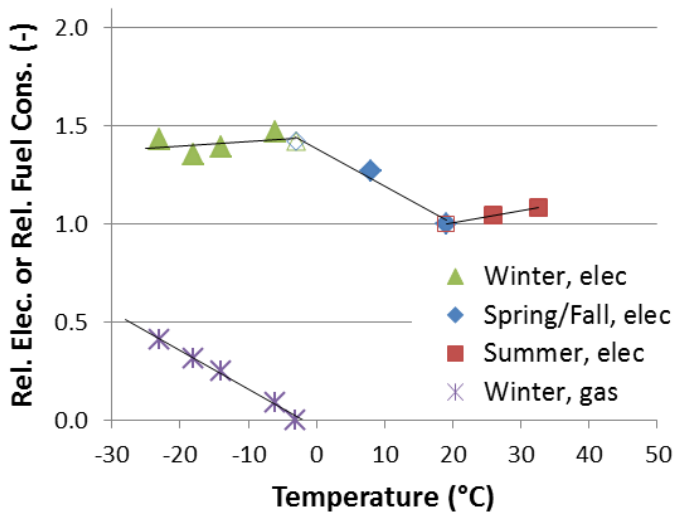

c) PHEV (Volt 2), highway driving

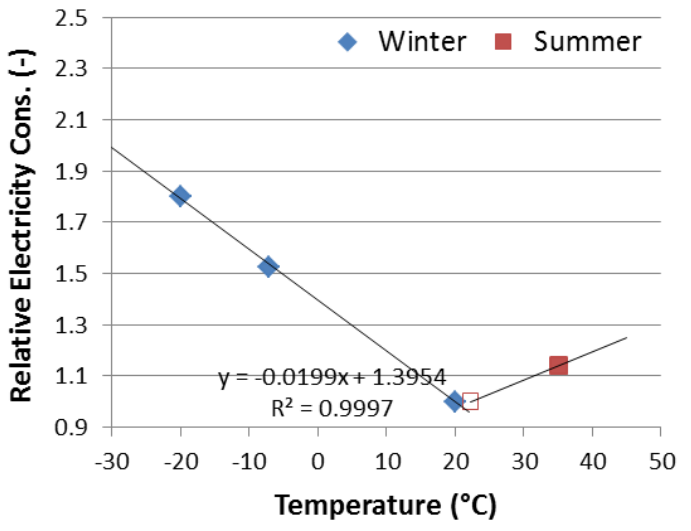

d) BEV, highway driving

Figure 7: Comparison of the relative energy consumption for City and Highway driving for the Volt 2 Plug-in Hybrid Electric Vehicle in Charge Depleting mode and Battery Electric Vehicles

driving at $-20{ }^{\circ} \mathrm{C}$, as a Relative Electricity Consumption value of 2.9 was calculated for the 'electricity only' surrogate at this temperature.

\section{Conclusions}

Two test programs were conducted to investigate the on-road performance of model year 2012 Chevrolet Volts in Ottawa, Ontario, Canada. The vehicles were tested during various seasons of the year over city and highway routes (among others) to record their performance over the full range of climate conditions representative for a large part of Canada (from $-27{ }^{\circ} \mathrm{C}$ to $+37^{\circ} \mathrm{C}$ ).

The test results showed that the Volt needs the least amount of electricity (in electric mode) or fuel (in hybrid mode) when operated at ambient temperatures of $20-25{ }^{\circ} \mathrm{C}$. Cabin conditioning during hot summer weather resulted in an increase in the Volt's energy consumption of 5-20\%, with city driving taking the higher end of this range. When the Volt was driven in charge sustaining mode in extreme winter temperatures $\left(-25^{\circ} \mathrm{C}\right)$, it consumed $20-30 \%$ more fuel than at $22{ }^{\circ} \mathrm{C}$. In charge depleting mode, the electricity consumption of the Volt rose strongly with decreasing temperatures. Around $0{ }^{\circ} \mathrm{C}$ the Volt's electricity consumption had increased by $50 \%$ for highway driving and by $100 \%$ for city driving. Below $-5{ }^{\circ} \mathrm{C}$, the Volt would intermittently operate the ICE to assist in heating and to propel the vehicle. In this 'mixed' type of operation, the Volt would consume substantial amounts of both electricity and gasoline at ambient temperatures of $-25^{\circ} \mathrm{C}$.

A 'Gasoline Displacement Factor' was introduced, which reflects the amount of grid electricity needed in CD mode to replace one litre 
of gasoline used for driving the Volt in CS mode. Test results show very low Gasoline Displacement Factors of $2-3.5 \mathrm{kWh} / \mathrm{L}$ for the Volts in summer driving, illustrating the superior efficiency of electric drive over engine use under these conditions. Much higher values of $3-9$ $\mathrm{kWh} / \mathrm{L}$ were observed for winter driving due to the relatively inefficient intermittent operation of the internal combustion engine when assisting in heating the cabin and the battery and to supply power to propel the vehicle. At extremely low temperatures, it may be more economical for Volt owners to operate their vehicle in CS mode, or to postpone $\mathrm{CD}$ mode operation until later in the day when temperatures may be somewhat higher.

The Volt's relative performance under extreme temperature conditions was also compared to that of conventional gasoline vehicles, hybrid electric vehicles and battery electric vehicles. In charge sustaining mode, the Volt has comparable or better performance in winter than other fuel burning vehicle types (conventional gasoline vehicles, hybrid electric vehicles), while in summer it needs considerably less additional energy for cabin conditioning, especially for highway driving. The performance of the Volt operating in charge depleting mode was more or less comparable to that of the tested battery electric vehicles, except in sub-zero temperatures, when the Volt would intermittently operate the internal combustion engine for additional heating and propulsion. In this 'mixed' operating mode, the Volts needed more energy, especially in city driving.

\section{Nomenclature}

\begin{tabular}{|c|c|}
\hline $\mathrm{AC}$ & Alternating current (grid) \\
\hline $\mathrm{CD}$ & Charge depleting \\
\hline$C h_{e f f}$ & Efficiency of charging (\%) \\
\hline $\mathrm{CS}$ & Charge sustaining \\
\hline $\mathrm{DC}$ & Direct current (battery) \\
\hline$D_{\text {tot } i}$ & $\begin{array}{l}\text { Total distance of repeat } \mathrm{i} \text { of a } \\
\text { specific drive cycle }(\mathrm{km})\end{array}$ \\
\hline Eac $_{\text {grid }}$ & $\begin{array}{l}\text { Total AC grid electricity consumed } \\
\text { for recharging the battery (Wh) }\end{array}$ \\
\hline$E C d c_{c y c l e}$ & $\begin{array}{l}\text { Specific DC battery energy } \\
\text { consumption for a cycle }(\mathrm{Wh} / \mathrm{km})\end{array}$ \\
\hline$E d c_{\text {battery }}$ & $\begin{array}{l}\text { Total DC battery energy discharged } \\
\text { during driving (Wh) }\end{array}$ \\
\hline Edc cycle $i$ & $\begin{array}{l}\text { Total DC battery energy discharged } \\
\text { for repeat number } \mathrm{i} \text { of a specific } \\
\text { cycle in a given test (Wh) }\end{array}$ \\
\hline$G_{\text {cycle } i}$ & $\begin{array}{l}\text { Total gasoline consumed during } \\
\text { repeat } \mathrm{i} \text { of a specific cycle in a given }\end{array}$ \\
\hline
\end{tabular}

test (L)

$G C_{\text {cycle }} \quad$ Specific gasoline consumption of a cycle $(\mathrm{L} / \mathrm{km})$

\section{Acknowledgments}

Funding for this work was provided by Natural Resources Canada through the Program of Energy Research and Development.

The authors would also like to thank the ecoTECHNOLOGY for Vehicles Program from Transport Canada for providing detailed test data on BEVs for use in this study.

\section{References}

[1] L. Brooke, Special Report Meeting CAFÉ 2025, Automotive Engineering International, October 23, 2012.

[2] M. Douba, Carlson, F. Jehlik, J. Smart, S. White, Correlating Dynamometer Testing to In-Use Fleet Results of Plug-In Hybrid Electric Vehicles, EVS24 International Battery, Hybrid and Fuel Cell Electric Vehicle Symposium, Stavanger, Norway, May 13-16, 2009.

[3] J. Smart, J. Francfort, D. Karner, M. Kirkpatrick, S. White, U.S. Department of Energy - Advanced Vehicle Testing Activity: Plug-In Hybrid Electric Vehicle Testing and Demonstration Activities, EVS24 International Battery, Hybrid and Fuel Cell Electric Vehicle Symposium, Stavanger, Norway, May 13-16, 2009.

[4] M. Allen, FleetCarma, https://www.fleetcarma.com/nissan-leafchevrolet-volt-cold-weather-range-loss-electricvehicle/, Accessed on 2015-02-04.

[5] A. Conde, A. Loiselle-Lapointe, H. Ribberink, Chevrolet Volt On-Road Test Programs in Canada. Part 1: Effects of Drive Cycle, Ambient Temperature and Accessory Usage on Energy Consumption and Range, Proceedings EVS28, Seoul, Korea, 3-6 May 2015.

[6] Argonne National Laboratory, Downloadable Dynamometer Database, http://www.transportation.anl.gov/D3/index.html, accessed December 2013.

[7] E. Nam, Drive Cycle Development and RealWorld Data in the United States, WLTP meeting, Geneva, Switzerland, January 15, 2009. 


\section{Authors}

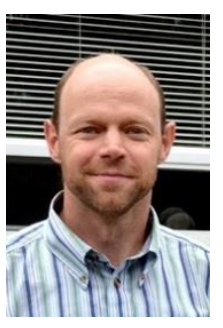

Hajo Ribberink has a M.Sc. degree in Applied Physics. He uses modelling and simulation to assess new and innovative technologies for the production or use of electricity and/or heat. He leads CanmetENERGY's research in the field of integration aspects of electric vehicles and the electrical grid.

Aaron Loiselle-Lapointe is a Project Engineer at the Emissions Research and Measurement Section of Environment Canada where he oversees a variety of mobile source programs. Currently he is leading the electric mobility portfolio at the ERMS. Aaron has a M.Sc. in Environmental Engineering and a Bachelor Degree in Aerospace Engineering.

Aaron Conde has a M.Eng. in Environmental Engineering from Carleton University and a B.ASc. in Engineering Chemistry from Queen's University. $\mathrm{He}$ is currently responsible for several light-duty vehicle and electric mobility chassis dynamometer projects at the Emissions Research and Measurement Section of Environment Canada. Aaron has experience studying the onroad performance of PHEVs as well as analyzing high-voltage battery signals from electric vehicle drivetrains. 